\title{
The pressure profile of the gastroduodenal junctional zone in dogs ${ }^{1}$
}

\author{
BENNO M. BRINK, JERRY F. SCHLEGEL, AND CHARLES F. CODE \\ From the Mayo Clinic and Mayo Foundation, Rochester, Minnesota, U.S.A.
}

\begin{abstract}
EDITORIAL SYNOPSIS A narrow zone of raised pressure has been found at the gastroduodenal junction in fasting dogs, indicating that the diameter of the lumen is less than $1.7 \mathrm{~mm}$. most of the time. Instillation of acid into the duodenum increased the pressure in the junctional zone and stimulated duodenal motility while antral motility decreased. Instillation of olive oil into the duodenum also increased the pressure at the junction but only after a lapse of 15 minutes whereas antral motility was inhibited immediately.
\end{abstract}

The gastroduodenal junction or pylorus has been regarded by some investigators as a true sphincter while others have questioned whether it performs such a function. Cannon (1898) concluded from his radiological observations on cats that the junctional zone functioned as a sphincter and was closed except when a peristaltic antral contraction approached. Gershon-Cohen and Shay (1937) observed in human subjects that the introduction of hydrochloric acid or of fat into the duodenum delayed gastric empyting. In their radiological study, the junctional zone seemed to be closed by these agents. The results of others have implied that the region does not act as a sphincter. For example, Brody, Werle, Meschan, and Quigley (1940), using air-filled, open-tip catheters on either side of the pylorus in dogs, found no sustained pressure elevation in the zone. The introduction of acid or of fat into the duodenum produced relaxation in the region rather than contraction (Quigley, Read, Radzow, Meschan, and Werle, 1942; Quigley, Werle, Ligon, Read, Radzow, and Meschan, 1941). Atkinson, Edwards, Honour, and Rowlands (1957) detected no increase of pressure as small air-filled balloons and air-filled, open-tipped tubes were withdrawn through the gastroduodenal junctional zone of human beings.

This study was undertaken to determine, first, if a zone of elevated pressure was present between the stomach and duodenum of healthy, fasted, unanaesthetized dogs using methods not previously employed in this region, and, secondly, to test the effect of acid or fat in the duodenum on the pressures in the junctional region.

${ }^{1}$ This investigation was supported in part by research grant A-2015 from the National Institutes of Health, Public Health Service.
METHODS

Healthy, adult mongrel dogs weighing from $8 \cdot 3$ to $14 \mathrm{~kg}$. were used. Seven were males and two were females. With the dog under pentobarbital or ether anaesthesia, one Vitallium cannula was inserted into the stomach just proximal to the pyloric antrum and another into the duodenum distal to the bile duct. The cannulae were brought out through the anterior abdominal wall in the mammary line on either side. The animals recovered from the operation in a few days and gained or maintained body weight throughout the period of study. The cannulae were plugged between observations.

A battery of small pressure-detecting units of different lengths and cross-sectional diameters was used in an attempt to define the diameter of the gastroduodenal junctional zone as well as to record pressures within it (Code and Schlegel, 1958). These units included a waterfilled polyethylene tube with internal and external diameters of 1.2 and $1.7 \mathrm{~mm}$., respectively, in which a lateral orifice had been cut near the distal end (referred to as an open-tip tube) and three small balloons that measured 3.5 by $3.5,5$ by 10 , and 7 by $7 \mathrm{~mm}$., respectively (Fig. 1). The balloons were filled, but not distended, with water and were attached to the open ends of water-filled polyethylene tubes that terminated in strain-gauge pressure transducers (Statham P23De). Breathing was recorded simultaneously by means of a belt pneumograph. Outputs of the various transducers were led to galvanometers, deflections of which were recorded photokymographically.

The animals were trained to lie quietly in the supine position. They were unanaesthetized during the tests and had fasted for at least $\mathbf{1 8}$ hours beforehand. The pressure profile of the gastroduodenal junctional zone was determined by a modification of the method of Fyke and Code (1955). In most tests, the pressure-detecting units were inserted through the gastric cannula and manoeuvred through the gastric antrum, junctional zone, and duodenum to the duodenal cannula. After recording resting 


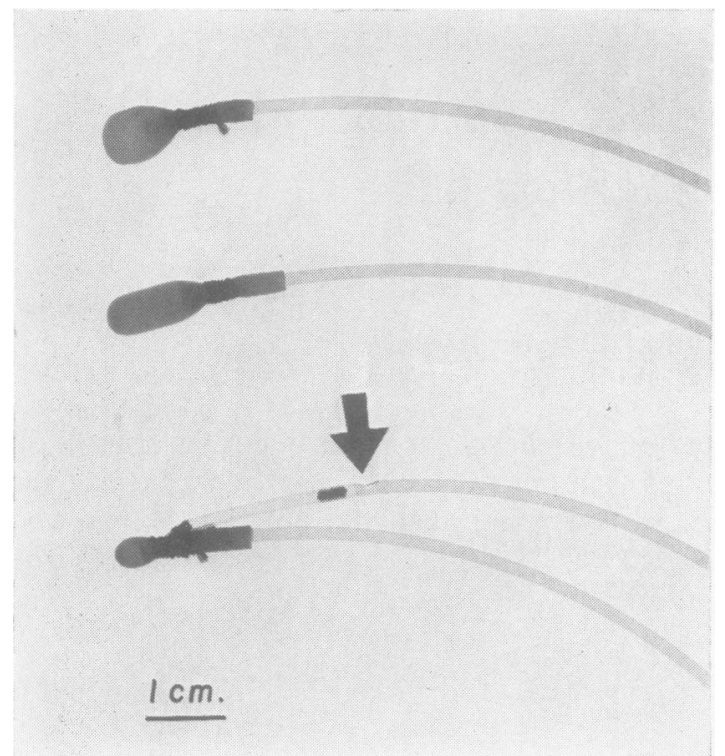

FIG. 1. Water-filled balloons and tube with lateral orifice (open-tip tube) used in the detection of pressures at the gastroduodenal junction. From above downward, the balloons when filled are 7 by $7 \mathrm{~mm}$., 5 by $10 \mathrm{~mm}$., and 3.5 by $3.5 \mathrm{~mm}$.

pressures and duodenal contractions for several minutes, the units were withdrawn in a stepwise fashion, $0.5 \mathrm{~cm}$. at a time, toward the gastric cannula. A pause of about 10 seconds was allowed after each withdrawal to permit recording the pressures. The withdrawal terminated at the gastric cannula. In some tests the pressure detectors were inserted through the duodenal cannula into the gastric antrum and withdrawn in the opposite direction.

After the fasting studies the pressure-detecting units were again placed in the duodenum. A second withdrawal was performed during instillation into the duodenum of either $0.1 \mathrm{~N}$ hydrochloric acid at a rate of $6 \mathrm{ml}$. per minute for eight minutes or olive oil at a rate of $2 \mathrm{ml}$. per minute for eight minutes. Fifteen to 20 minutes after the instillations, a third withdrawal was done.

The following measurements were made. The mean resting antral pressure during each test was determined and was used as the reference or 'zero' for all other pressure measurements. The resting pressures (the pressure recorded between contractions) in the duodenum and in each $0.5 \mathrm{~cm}$. of the junctional zone were determined. The pressure profiles of the junction obtained in this manner were arranged with the $0.5-\mathrm{cm}$. segment having the greatest pressure in each profile as the common point of spatial reference. The mean pressure profiles detected by each pressure-sensitive unit, under each of the different conditions of the experiments, were defined in this manner and compared statistically. The mean length of the zone of elevated pressure and the mean duodenal pressure were determined. The location of the zone in relation to the presence of duodenal and antral motility also was defined in each group of tests.

\section{RESULTS}

FASTING STUDIES When the pressure-detecting unit was placed in the duodenum of the fasting dog, typical rhythmic and non-rhythmic duodenal type I waves usually were recorded. As the unit was withdrawn proximally at $0.5-\mathrm{cm}$. intervals, duodenal motility continued to be recorded until the unit reached the gastroduodenal junctional zone. This zone was recognized by two features, an increase in resting pressure and a change in the pattern of motility from duodenal to antral (Fig. 2).

The magnitude of the change in resting pressure at the junctional zone varied with the cross-sectional diameter of the pressure-detecting instrument used (Figs. 2 and 3). With the open-tip tube, a measurable elevation of pressure was recorded in the junction in 15 of 25 tests on five dogs (Table). The mean maximal pressure was $3.2 \mathrm{~cm}$. of water more than the mean resting antral pressure (Table). In most tests, the point of maximal pressure was either at the centre of the zone or near it, giving it a rather symmetrical profile in the records (Fig. 3). The mean length of the zone was $1 \cdot 1 \mathrm{~cm}$. (Table).

With balloons, an increase of pressure at the junction was detected more often. In 12 of 15 studies on four dogs, an increase of pressure was recorded by the 3.5 by $3.5-\mathrm{mm}$. balloon. The incidence increased to $97 \%$ of 58 observations on four dogs with the 7 by $7-\mathrm{mm}$. balloon. The larger the diameter of the pressure-detecting unit (Table, Fig. 3), the greater were the pressures recorded throughout the zone. The mean maximal pressures recorded by the balloons were $5.7 \mathrm{~cm}$. of water with the 3.5 by $3.5-\mathrm{mm}$. balloon, $7.4 \mathrm{~cm}$. of water with the 5 by $10-\mathrm{mm}$. balloon, and $11.3 \mathrm{~cm}$. of water with the 7 by $7-\mathrm{mm}$. balloon. (Table) As expected, the zone was slightly longer when balloon detectors were used (Table).

The zone of elevated pressure was located close to the junction as identified by the change in motor action recorded during the withdrawals. In the fasted dogs, the only pressure waves detected in the zone of elevated pressure were antral. The last duodenal contraction to be recorded during the withdrawals was 2 to $2.6 \mathrm{~cm}$. distal to the point of maximal pressure in the region.

EFFECT OF ACID IN THE DUODENUM ON PRESSURE PROFILE OF THE JUNCTION TwO groups of control tests were done on three dogs to determine the effect of repeated withdrawals of pressure-detecting devices through the junctional zone and the effect of the instillation of a neutral solution into the duodenum on the pressures in the region. In the first group, a 7 by $7-\mathrm{mm}$. balloon was withdrawn twice in quick 
OPEN-TIP TUBE

$\operatorname{Dog} A$<smiles>C[C@H]1O[13CH]2[13CH]C[C@H]12</smiles>
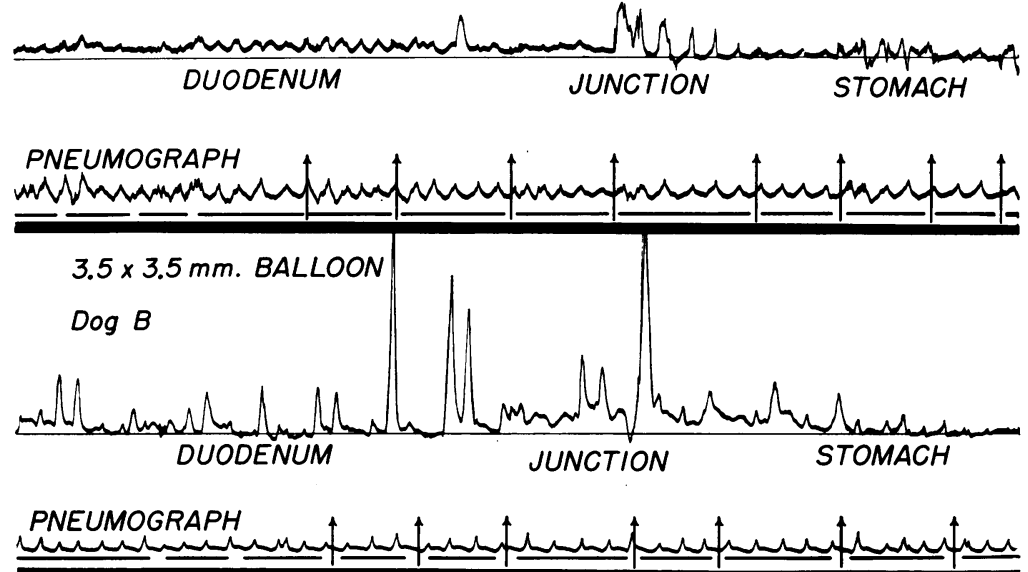

FIG. 2. Pressure profiles of canine gastroduodenal junction in fasting dogs $A$ and $B$, as detected by the open-tip tube and the 3.5 by $3.5 \mathrm{~mm}$. and 7 by 7-mm. balloons. In this and subsequent illustrations the pressure detecting units were withdrawn orad $0.5 \mathrm{~cm}$. at each vertical arrow. Notice the rise of pressure over a short distance as the units passed through the junction between duodenum and stomach.

$7 \times 7 \mathrm{~mm}$. BALLOON

$\operatorname{Dog} A$

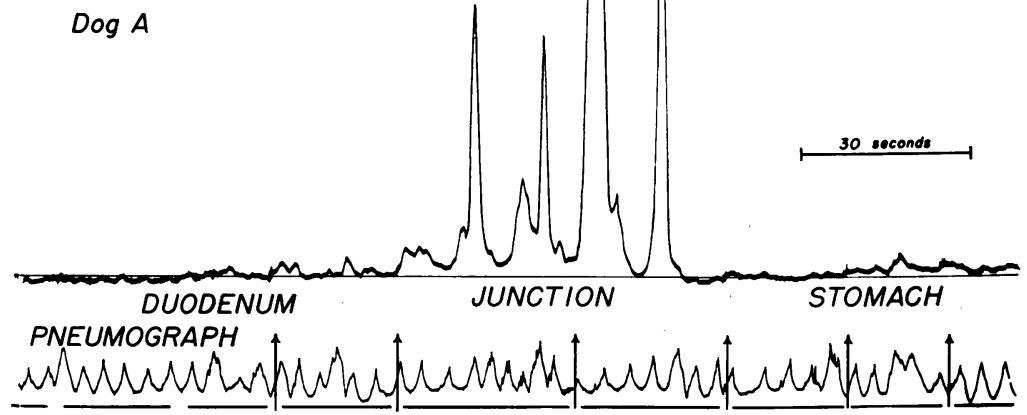

TABLE

CANINE GASTRODUODENAL JUNCTIONAL ZONE UNDER FASTING CONDITIONS

Detecting Unit

\begin{tabular}{|c|c|c|c|c|c|}
\hline \multirow{3}{*}{$\begin{array}{l}\text { No. of } \\
\text { Dogs }\end{array}$} & \multirow{3}{*}{$\begin{array}{l}\text { No. of } \\
\text { Tests }\end{array}$} & \multicolumn{4}{|c|}{ Pressure Elevation at Junctional Zone } \\
\hline & & \multirow[t]{2}{*}{ Incidence Test } & \multirow[t]{2}{*}{$\begin{array}{l}\text { Mean Width } \\
(\mathrm{cm} .)\end{array}$} & \multicolumn{2}{|c|}{$\begin{array}{l}\text { Mean Maximal Pressure } \\
\left(\mathrm{cm} . \mathrm{H}_{2} \mathrm{O}\right)\end{array}$} \\
\hline & & & & All Tests & $\begin{array}{l}\text { Tests with } \\
\text { Elevation }\end{array}$ \\
\hline
\end{tabular}

Open-tip tube

Balloon

3.5 by $3.5 \mathrm{~mm}$

5 by $10 \mathrm{~mm}$.

7 by $7 \mathrm{~mm}$. 


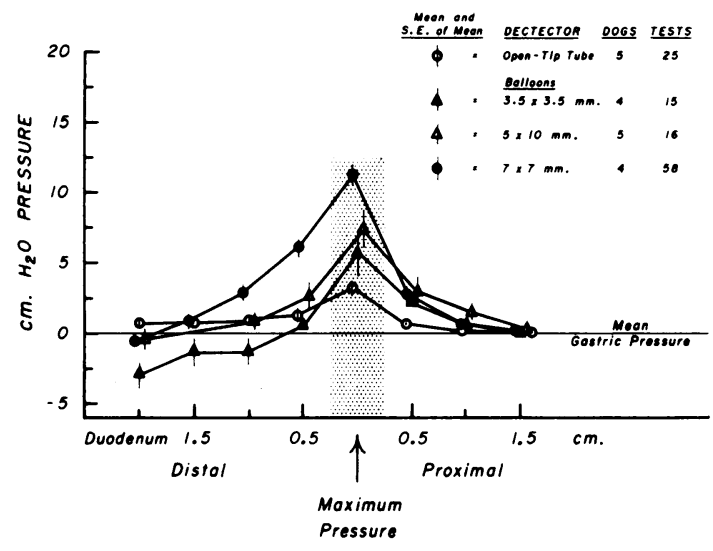

FIG. 3. Mean pressures recorded at the gastroduodenal junction in fasting dogs by open-tip and balloon detectors.

succession and then a third time 20 minutes later. In the second group, $6 \mathrm{ml}$. of Tyrode's solution was instilled per minute into the duodenum for eight minutes and the balloon was withdrawn during and after the instillation. The mean maximal pressure encountered in the junction during the first withdrawal without the instillation of Tyrode's solution was not significantly different from that obtained under any of the other circumstances in either of the two groups of tests. Likewise, the width and the location of the maximal pressure of the zone did not change.

The instillation of $0.1 \mathrm{~N}$ hydrochloric acid into the duodenum at a rate of $6 \mathrm{ml}$. per minute for eight minutes produced marked changes in the pressure profile of the junction and in duodenal and antral motility (Fig. 4). With acid in the duodenum, a zone of elevated pressure was detected during 14 of 17 withdrawals in five dogs with the open-tip tube, during six of seven withdrawals in four dogs with the 3.5 by $3.5-\mathrm{mm}$. balloon, and during nine of 10 withdrawals in four dogs with the 7 by $7-\mathrm{mm}$. balloon. Each unit detected a greater maximal pressure during the instillation of acid than during the withdrawal just before the instillation. The mean maximal pressure defined by the lateral orifice increased from $3.7 \mathrm{~cm}$. of water during control tests
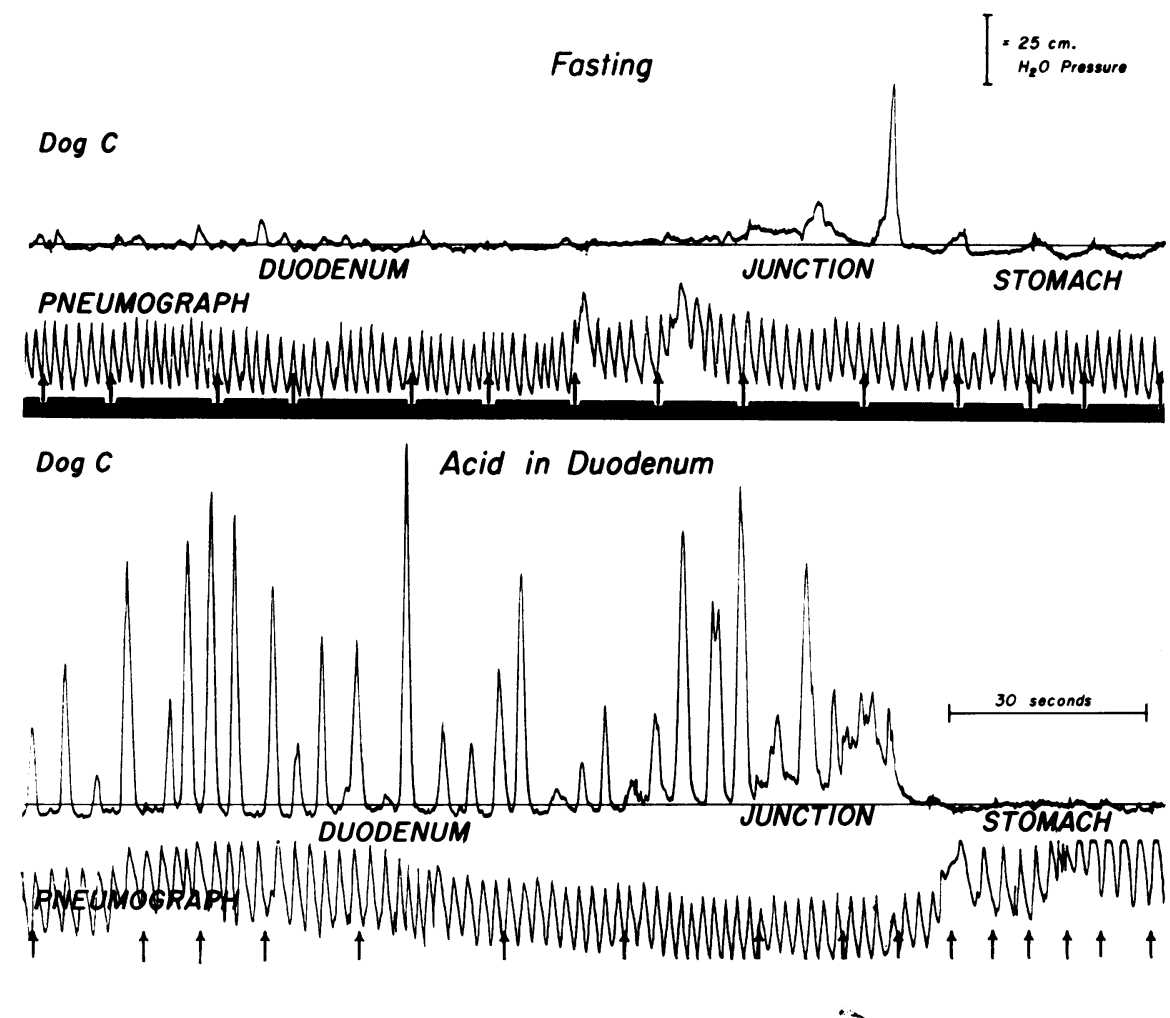

FIG. 4. The effect of acid instillation into the duodenum on the pressure profiles of the gastroduodenal junction and duodenal motility in a dog using a 7 by 7-mm. balloon detector. 
to $7 \cdot 3 \mathrm{~cm}$. of water during the acid instillation, from 8.4 to $16.8 \mathrm{~cm}$. of water with the 3.5 by $3.5-\mathrm{mm}$. balloon, and from 7.9 to $16.4 \mathrm{~cm}$. of water with the 7 by $7-\mathrm{mm}$. balloon (Fig. 5). The pressures throughout the zone were increased although its mean width did not change appreciably (Fig. 5).

The type of motor activity recorded in the zone of elevated pressure changed with the instillation of acid. During control studies, only antral pressure waves were recorded. These became duodenal in character when acid was instilled in the duodenum (Fig. 4). The last duodenal contractions to be recorded as the balloons were withdrawn were on the gastric side of the point of maximal pressure, while during control studies they were 2 or more $\mathrm{cm}$. distal to this point (Fig. 4).

Duodenal contractions (type I waves) increased greatly in strength as acid was instilled into the duodenum (Fig. 6). Motor activity in the antrum, on the other hand, ceased promptly with the instillation of acid in the duodenum and little or no activity was detected for some time afterwards (Fig. 6). The enhanced duodenal motility soon disappeared when the instillation was stopped.
Fifteen to 20 minutes after the instillation of acid, mean maximal pressures in the junctional zone and in the duodenum had nearly returned to fasting values (Fig. 5), and the zone of elevated pressure again was surmounted by antral contractions.

EFFECT OF FAT IN THE DUODENUM Olive oil was instilled twice into the duodenum of four dogs at a rate of $2 \mathrm{ml}$. per minute for eight minutes. During the instillation, little change occurred in duodenal motility or in the mean maximal pressure of the junctional zone (Figs. 7 and 8), but antral motility was inhibited (Fig. 9).

Fifteen to 20 minutes after the instillation, a significant increase of pressure was recorded throughout the junctional zone by each pressuredetecting unit (Figs. 7 and 8). The mean maximal pressure had increased from a fasting level of $2 \cdot 6 \mathrm{~cm}$. to $4.5 \mathrm{~cm}$. of water with the open-tip tube, from 3.2 to $7.8 \mathrm{~cm}$. of water with the 3.5 by $3.5-\mathrm{mm}$. balloon, and from 12.3 to $22.1 \mathrm{~cm}$. of water with the 7 by $7-\mathrm{mm}$. balloon. The mean width of the region was unaltered. No change was seen in duodenal pressure or motility. Antral contractions were still inhibited.
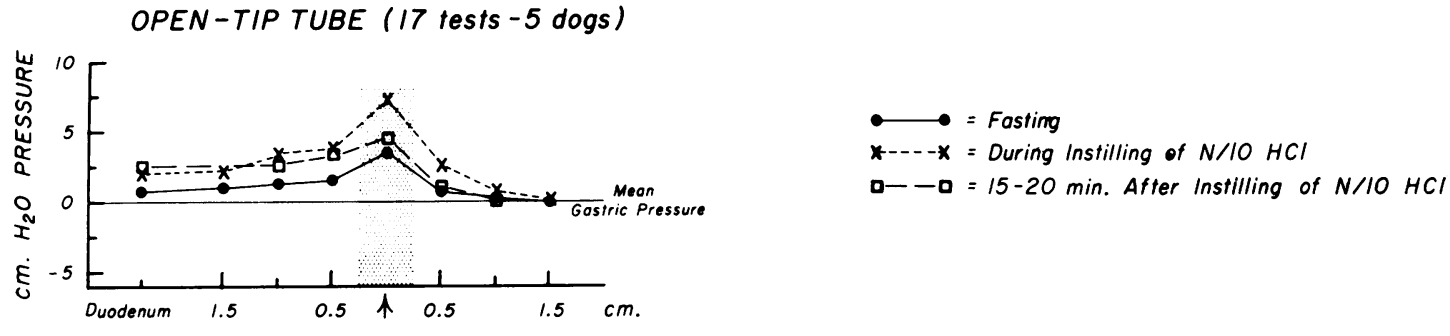

\section{$3.5 \times 3.5 \mathrm{~mm}$. BALLOON}

( 7 tests -4 dogs)
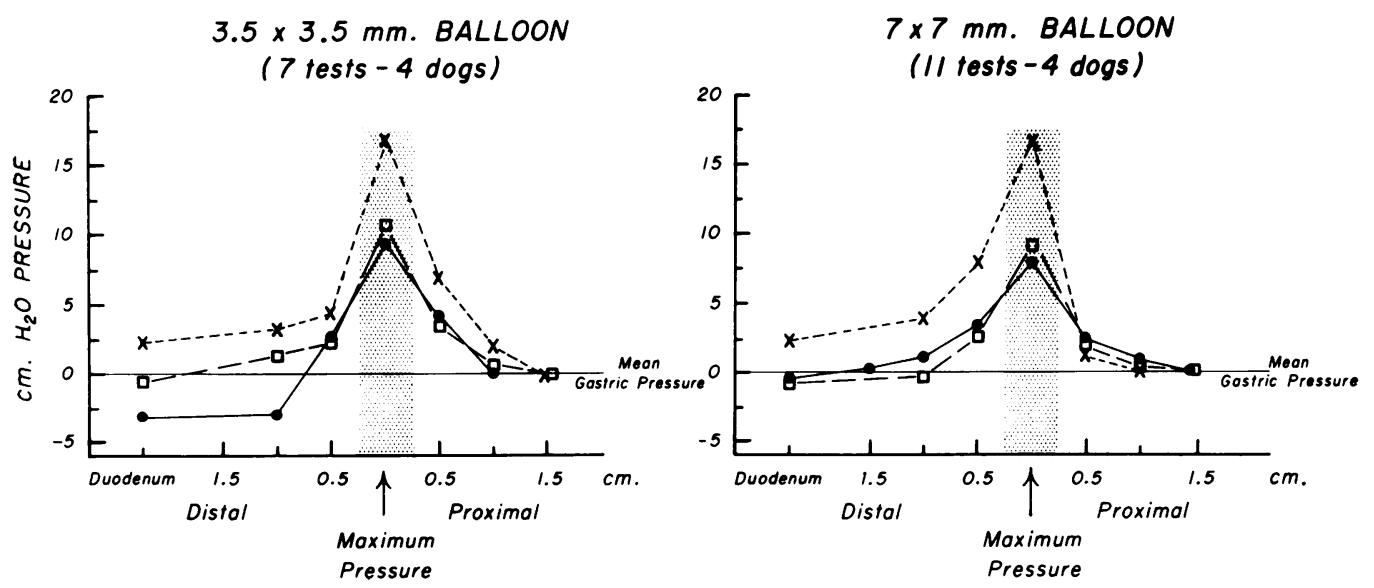

FIG. 5. Mean pressures in the gastroduodenal junction of dogs before (fasting), during, and after the instillation of acid in the duodenum, using open-tip tubes and tiny balloon detectors. 

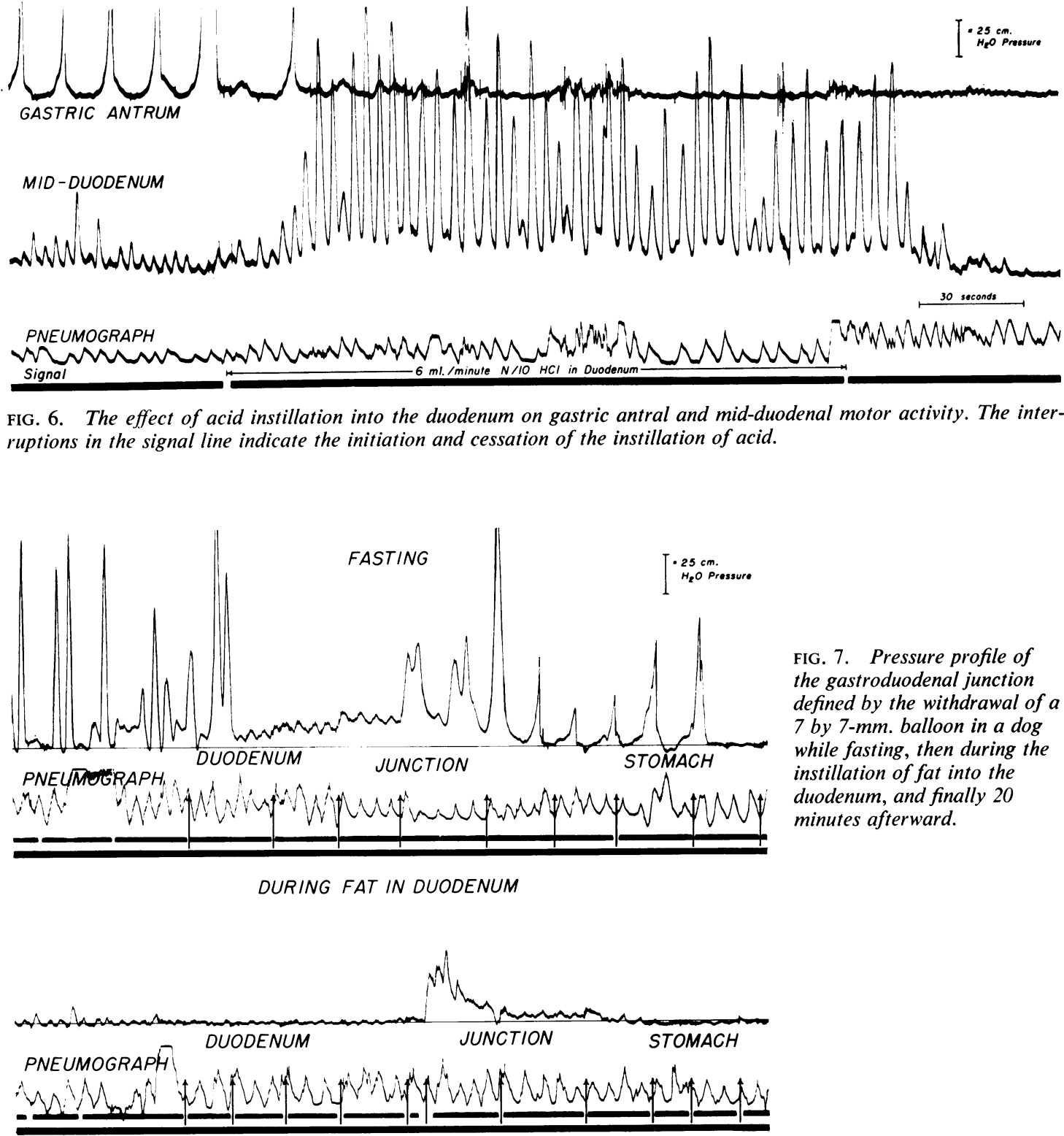

FIG. 7. Pressure profile of the gastroduodenal junction defined by the withdrawal of $a$ 7 by 7-mm. balloon in a dog while fasting, then during the instillation of fat into the PNELMNERAPH duodenum, and finally 20 minutes afterward.

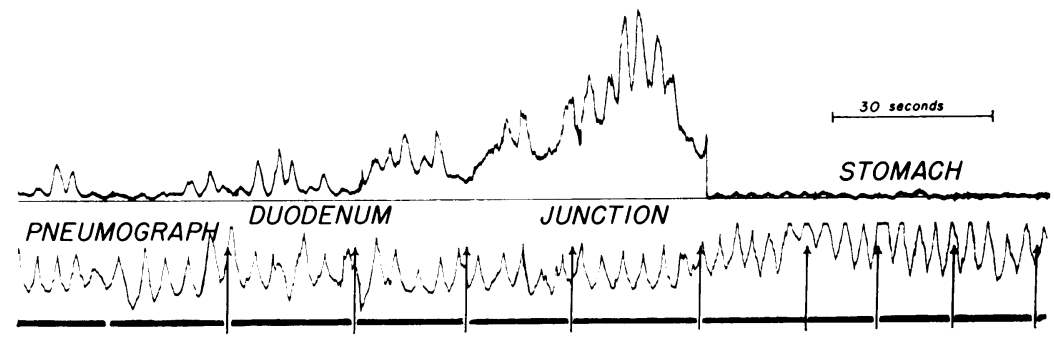



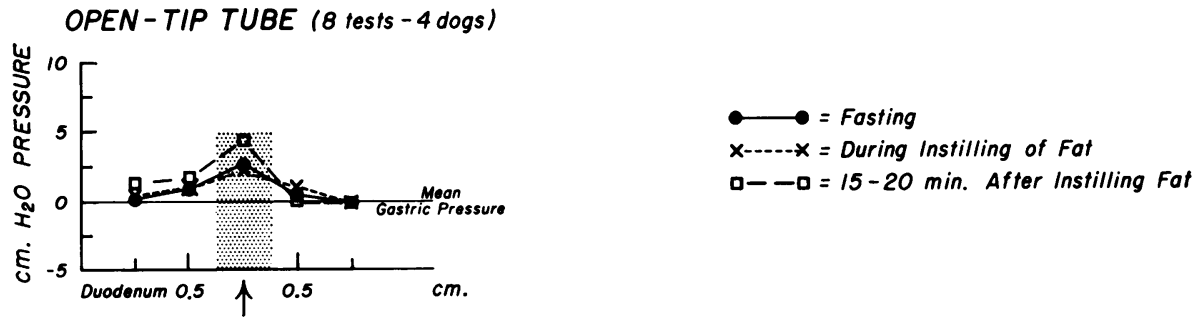

$3.5 \times 3.5 \mathrm{~mm}$. BALLOON

$7 \times 7 \mathrm{~mm}$. BALLOON

( 8 tests -4 dogs)

FIG. 8 .
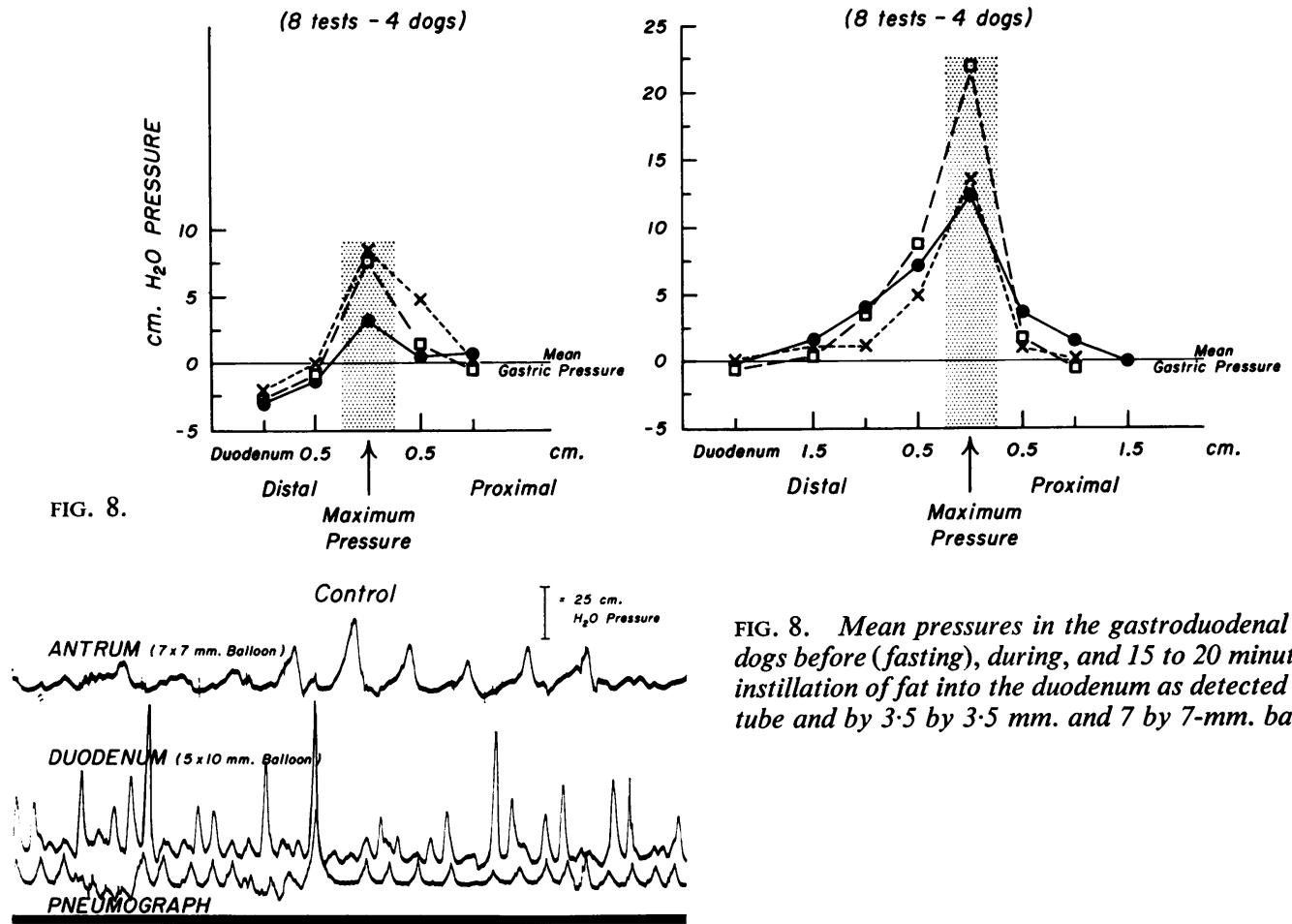

FIG. 8. Mean pressures in the gastroduodenal junction of dogs before (fasting), during, and 15 to 20 minutes after the instillation of fat into the duodenum as detected by open-tip tube and by 3.5 by $3.5 \mathrm{~mm}$. and 7 by 7-mm. balloons.

5 minutes after Fat

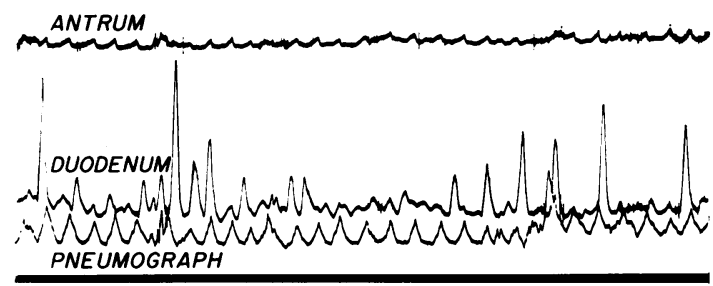

20 minutes after Fat

ANTRUM

FIG. 9. Prolonged inhibition of gastric antral motility after instillation of fat in the duodenum.

FIG. 9. 


\section{COMMENT}

Other investigators, using air-filled pressure detecting systems, have not found a region of increased pressure at the gastroduodenal junction (Atkinson, et al., 1957; Brody et al., 1940; Wheelon and Thomas, 1920). Therefore, they have concluded that the zone is usually open. In the studies of Wheelon and Thomas (1920) and those of Brody et al. (1940), the pressure-detecting units were left in place, in or on either side of the pyloric canal. The zone of elevated pressure found in our study was very narrow and could have been missed by detectors in a fixed position.

Using air-filled, open-tipped tubes and air-filled tiny balloons in studies on human beings, Atkinson et al. (1957) did not detect a rise of pressure during withdrawals through the junction. If their tubing was unkinked and if their balloons did not seal off the tips of their tubes, the zone must have been open when their units passed through the region. In the fasting dog, the pyloric canal or sphincter is closed only during a part of each antral cycle. In human beings three cycles occur each minute. If the sequence of closure in humans is the same as that in dogs, it is unlikely that during the withdrawal of a series of balloons a period of closure would be missed by all of them. It seems more probable that the canal was open during their tests. This would very likely occur in the absence of antral or duodenal motor activity. The effects of acid and fat were not tested by Atkinson et al. (1957).

The results of our study indicate that in fasting dogs the gastroduodenal junctional zone has a crosssectional diameter of less than $1.7 \mathrm{~mm} .60 \%$ of the time and that the orifice is nearly always less than $7 \mathrm{~mm}$. (smaller than the 7 by $7-\mathrm{mm}$. balloon).

The instillation of $0 \cdot 1 \mathrm{~N}$ hydrochloric acid into the duodenum produced a pronounced increase in duodenal motility and an increase in the pressure in the junctional zone. The increase in pressure at the junction may help to prevent reflux into the stomach during the period of augmented duodenal motility. Thomas, Crider, and Mogan (1934) noted a momentary increase of pressure and motility in the junction after a single injection of hydrochloric acid into the duodenum. This was followed by a decrease in pressure and an inhibition of motility. The difference between their findings and ours is probably related to the longer period of instillation of acid in our tests. Quigley et al. (1942) found only a decrease in pressure and an inhibition of motility in the region when acid was injected into the duodenum, but their fixed detectors may not have been located at the site of the increased pressure. Their results suggest that their detectors rested in the terminal antrum, which is inhibited by acid in the duodenum.

The instillation of olive oil into the duodenum produced no immediate effect except the inhibition of gastric antral motility. When tested 15 to 20 minutes later, however, a definite increase in the pressures in the junction was present, while antral motility was still inhibited. The delay may be due to the time needed for emulsification of the olive oil (Menguy, 1960). Gershon-Cohen and Shay (1937) and Waugh (1936) interpreted their radiological observations as indicating that fat in the duodenum closed the pylorus. No previous manometric studies have confirmed their interpretation. With fixed detectors, Quigley et al. (1941) found that fat decreased pressures in the junctional region but, as previously mentioned, their detectors may not have been located in the segment responding with increased pressure. Our results suggest their detectors lay on the antral side of the high pressure zone when fat or acid was in the duodenum.

The changing character of the motor activity surmounting the zone of elevated pressure indicates that either the junction migrates, being sometimes located in the terminal antrum or sometimes in the first segment of the duodenum, or the character of the motor action in the junction can change from antral to duodenal. A slight shift in location seems possible.

\section{SUMMARY}

In healthy, unanaesthetized, fasting dogs a zone of elevated pressure was detected in the gastroduodenal junction in $60 \%$ of the studies with a lateral orifice tube, $1.7 \mathrm{~mm}$. in diameter. With 3.5 by $3.5-\mathrm{mm}$., 5 by $10-\mathrm{mm}$., and 7 by $7-\mathrm{mm}$. balloons, the incidence increased progressively from 80 to $97 \%$ with the largest balloon. The mean maximal pressure recorded in the junction by the different detectors ranged from 3.2 to $11.3 \mathrm{~cm}$. of water depending on their cross-sectional diameter. The mean width of the zone varied only from 1.1 to $1.6 \mathrm{~cm}$.

During the introduction of $48 \mathrm{ml}$. of $0.1 \mathrm{~N}$ hydrochloric acid into the duodenum over a period of eight minutes, the duodenal activity and the mean maximal pressure in the junction increased while antral motility decreased. During the instillation of $16 \mathrm{ml}$. of olive oil over an eight-minute period, no significant change was noted in the mean pressures in the junction, although antral activity was inhibited; but 15 to 20 minutes later the mean maximal pressures were increased in the junction, and antral activity remained inhibited.

\section{REFERENCES}

Atkinson, M., Edwards, D. A. W., Honour, A.J., and Rowlands, E. N. (1957). Comparison of cardiac and pyloric sphincters: a manometric study. Lancet, 2, 918-922. 
Brody, D. A., Werle, J. M., Meschan, I., and Quigley, J. P. (1940). Intralumen pressures of the digestive tract, especially the pyloric region. Amer. J. Physiol., 130, 791-801.

Cannon, W. B. (1898). The movements of the stomach studied by means of the roentgen rays. Ibid., 1, 359-382.

Code, C. F., and Schlegel, J. F. (1958). The pressure profile of the gastroesophageal sphincter in man: an improved method of detection. Mayo Clin. Proc., 33, 406-414.

Fyke, F. E., Jr., and Code, C. F. (1955). Resting and deglutition pressures in the pharyngo-esophageal region. Gastroenterology, 29, 24-34.

Gershon-Cohen, J., and Shay, H. (1937). Experimental studies on gastric physiology in man. III. A study of pyloric control. The rôle of milk and cream in the normal and in subjects with quiescent duodenal ulcer. Amer. J. Roentgenol., 38, 427446.

Menguy, R. (1960). Role of biliary and pancreatic secretions in the inhibition of gastric motility by fat in the intestine. Amer. J. digest. Dis., 5, 792-800.
Quigley, J. P., Read, M. R., Radzow, K. H., Meschan, I., and Werle, J. M. (1942). The effect of hydrochloric acid on the pyloric sphincter, the adjacent portions of the digestive tract and on the process of gastric evacuation. Amer. J. Physiol., 137, 153-159.

-, Werle, J., Ligon, E. W., Jr., Read, M. R., Radzow, K. H., and Meschan, I. (1941). The influence of fats on the motor activity of the pyloric sphincter region and on the process of gastric evacuation studied by the balloon-water manometer and by optical manometer-fluoroscopic technics. Ibid., 134, 132-140.

Thomas, J. E., Crider, J. O., and Mogan, C. J. (1934). A study of reflexes involving the pyloric sphincter and antrum and their role in gastric evacuation. Amer. J. Physiol., 108, 683-700.

Waugh, J. M. (1936). Effect of fat introduced into the jejunum by fistula on motility and emptying time of the stomach. Arch. Surg., 33, 451-466.

Wheelon, H., and Thomas, J. E. (1920). Observations on the motility of the antrum and the relation of rhythmic activity of the pyloric sphincter to that of the antrum. J. Lab. clin. Med., 6, 124-143. 